\title{
Geoscientists online
}

\author{
Increasing numbers of geoscientists are nurturing an online presence. Nature Geoscience explores the potential \\ benefits of taking your professional life online.
}

$\Lambda$ lthough much can be said about scientists harnessing the tentacles of the Internet to communicate their science and engage with the public - for better or for worse - the Internet also hosts scientists' virtual business cards, whether or not a scientist chooses to engage more actively online. At its simplest, a professional online presence for a geoscientist is a webpage hosted by a university, institution or company that provides some information on his or her research activities. More involved options include signing up to Google Scholar, joining a dedicated researcher networking site such as ResearchGate or Academia.edu, or being active on social media sites such as Twitter or WeChat. As social media use by scientists escalates, we recognize how building an online profile can help to grow a scientific career.

Arguably, the main reason for a scientist to establish an online presence is to increase the visibility of his or her research. Such self-promotion is understandable: after investing what can amount to several years of work into gaining research funding, gathering data, performing analyses and publishing manuscripts in peer-reviewed journals, researchers want their work to be seen by the community. We often hear from our authors that one of the benefits they see in publishing in a selective journal such as Nature Geoscience is the enhanced visibility that their papers receive to both the geoscience community and - via media coverage - the public at large.

Scientists can increase the visibility of their research outputs too, both to fellow specialists and more broadly, by maintaining an online presence. For example, users of ResearchGate can upload preprints of their publications and 'followers' are alerted by automated e-mails, and preprint servers allow geoscientists to share their very latest research before peer review ${ }^{1}$. And, although data suggested that only $13 \%$ of scientists worldwide were active on Twitter in 2014 $\left(\right.$ ref. $\left.^{2}\right)$, the majority of scientists' Twitter

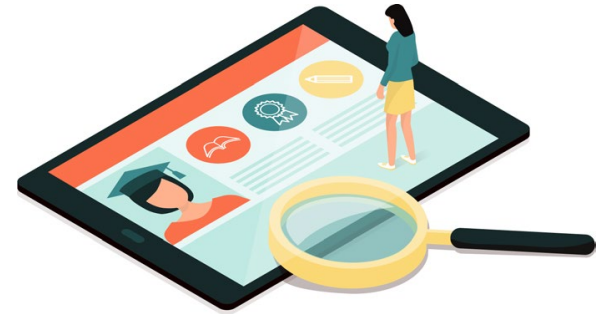

Credit: ElenaBs / Alamy Stock Vector

followers are fellow scientists ${ }^{3}$, suggesting that Twitter can be used to increase the visibility of research within professional networks.

Researchers might hope that the increased visibility online will pay off by boosting citation rates. Given that a researcher's $h$-index or related measure of citations can make or break applications for academic jobs, tenure and funding, this would be a significant benefit. There is plenty of anecdotal evidence supporting a link between citations and online presence, but there is limited evidence in the peer-reviewed literature. One study sponsored by Academia.edu found, perhaps unsurprisingly, that articles posted there received $58 \%$ more citations after 5 years than studies only available online through personal and departmental webpages $^{4}$. Other studies have found - albeit with several caveats - that the number of tweets about a paper can predict citations, perhaps even more than journal impact factor ${ }^{5,6}$.

The increased visibility that an online presence brings can enhance a researcher's $\mathrm{CV}$ in other ways. At Nature Geoscience, we often rely on geoscientists' online presence when vetting potential reviewers, even if just to confirm contact details. Having a webpage detailing research interests, skill set and publications is a great way to increase the likelihood of being invited to peer review. If such information were readily findable on the Internet for all earth scientists (and ideally available in an English version), it would help journals recruit from a more geographically representative pool of reviewers ${ }^{7}$. Having a webpage that is findable by Google search may also help attract invitations to attend workshops or present invited talks. All of these are considered as measures of community esteem in career or funding assessments.

Online activity can also lead to the formation of new international collaborations. In some cases, scientists who have never met have facilitated fruitful collaborations via online networking ${ }^{1}$. Traditionally of course, most scientific networking takes places at conferences, meetings and workshops. Here an online presence can help too: the long days of intense social interaction and scientific discussion can be viewed with anticipation or apprehension, depending on personality, and with some conferences growing bigger every year getting one's presentation noticed can be difficult. Virtual networking beforehand to arrange meetings can help with successful networking in the real world, and using tools such as Twitter to promote talks and posters can help presentations be noticed - in addition to allowing scientists to keep up with meetings remotely.

Scientists have many options for engaging with the scientific community online ${ }^{8}$. But even for those who prefer not to actively engage in science communication with the broader public, there is much to be gained professionally and scientifically from an online presence.

Published online: 1 October 2018 https://doi.org/10.1038/s41561-018-0248-8

\footnotetext{
References

1. Nat. Geosci. 11, 149 (2018).

2. Van Noorden, R. Nature 512, 126-129 (2014).

3. Côté, I. M. \& Darling, E. S. FACETS 3, 682-694 (2018).

4. Niyazov, Y. et al. PLoS ONE 11, e0148257 (2016).

5. Eysenbach, G. J. Med. Internet Res. 13, e123 (2011).

6. Peoples, B. K. et al. PLoS ONE 11, e0166570 (2016).

7. Nat. Geosci. 10, 615 (2017).

8. Bik, H. M. \& Goldstein, M. C. PLoS Biol. 11, e1001535 (2013).
} 